\title{
Oroileal transit of slow release 5-aminosalicylic acid
}

\author{
H Goebell, U Klotz, B Nehlsen, P Layer
}

\begin{abstract}
The predominant active anti-inflammatory moiety in chronic inflammatory bowel disease is 5-aminosalicylic acid (5-ASA). As unprotected 5-ASA is rapidly absorbed in the upper gastrointestinal tract several slow release preparations have been developed to permit passage of 5-ASA to the lower small bowel and to the colon. To investigate luminal kinetics and extent of the release of 5-ASA intraluminal concentrations and loads of this compound together with that of its main metabolite acetyl5-aminosalicylic acid (ac-5-ASA) were studied, over 15 hours after giving the slow release preparation Salofalk at a dose of $\mathbf{5 0 0} \mathbf{~ m g}$ orally together with a test meal. Plasma concentrations and urinary excretion were also measured. Six healthy volunteers swallowed an 11 lumen oroileal tube, which allowed marker perfusion, aspiration of luminal content from the duodenum, mid-jejunum, and ileum, and recording of intestinal motility. Emptying of 5-ASA into the duodenum started after emptying of the meal, together with the first phase III of interdigestive motility. Mean luminal concentrations of 5-ASA and ac-5-ASA increased continuously from duodenum (both: 15 to $30 \mu \mathrm{g} / \mathrm{ml}$ ) to ileum (60 to $110 \mu \mathrm{g} / \mathrm{ml}$ and 80 to $150 \mu \mathrm{g} / \mathrm{ml}$ respectively) over three hours and decreased over the next three hours. During 10 hours after eating, $30 \%$ of the total dose passed the ileum in solution and another $10 \%$ were excreted in urine. Thus about $60 \%$ reached the colon unreleased from tablets and another $30 \%$ were in solution. The ratio of 5-ASA and ac-5ASA in solution was about 1:1 in the duodenum and $1: 1.5$ to $1: 2$ in the more distal small intestine. The data suggest that the large quantities of intraluminal ac-5-ASA are generated in the intestinal mucosa and reach the lumen by back diffusion. The results show that most of the 5-ASA from this slow release preparation is delivered into the colon, which explains its effectiveness in ulcerative colitis. The considerable luminal concentrations already present in the distal ileum might justify therapeutic trials in Crohn's disease.

(Gut 1993; 34: 669-675)
\end{abstract}

Gastroenterology,

Department of Medicine,

University of Essen,

Germany

H Goebell

B Nehlsen

P Layer

Dr Margarete Bosch Institute of Clinical

Pharmacology, Stuttgart, Germany

U Klotz

Correspondence to:

Dr Harald Goebell, Division

of Gastroenterology

Department of Medicine,

University Hufelandstrasse

55, D 4300 Essen 1, Germany

Accepted for publication

16 September 1992

After giving salazosulphapyridine (SASP) by mouth it is split into 5-aminosalicylic acid (5-ASA) and sulphapyridine by bacteria in the colon. The active moiety to inhibit the inflammation in chronic inflammatory bowel disease has been shown to be 5-ASA. ${ }^{1}$ On the other hand, sulphapyridine, used as a carrier molecule for SASP, is responsible for most of the side effects of this compound. Therefore administration of 5-ASA alone seems attractive as a treatment of inflammatory bowel disease. Administration of 5-ASA to the distal intestine is difficult, however, because of its rapid absorption in the stomach and proximal small bowel; the compound is then acetylated and excreted in urine. $^{2-4}$

To overcome this problem, different galenic 5-ASA (mesalazine, mesalamine) preparations have been developed with the aim of slower release of the substance into the gut lumen, which should permit major delivery of 5-ASA to the ileum and the colon: coating with Eudragit $S$ (Asacol) or Eudragit $\mathrm{L}$ in combination with sodium carbonate/glycine buffering (Salofalk, Claversal), microgranules coated with ethylcellulose (Pentasa). With another approach, two molecules of 5-ASA are coupled (Dipentum) and released on bacterial cleavage in the colon. Luminal liberation of 5-ASA from these various preparations has been investigated in several studies, generally by measuring urinary or faecal excretion, or plasma appearance and disappearance rates of 5-ASA and its main metabolite acetyl-5-ASA (ac-5-ASA), to estimate kinetics and extent of its intraluminal release. ${ }^{3-7}$ Other approaches included radiographic tracings of a barium sulphate marker, ${ }^{38}$ scintigraphic tracings of indium-111 released from an Eudragit $\mathrm{L}$ coated tablet, ${ }^{9}$ or the recovery of 5-ASA from the ileostomy effluent of patients. ${ }^{111}$

Thus our understanding of the luminal fate of 5-ASA is largely based on indirect estimations. ${ }^{12-14}$ Although it is assumed that liberation of 5-ASA from slow release preparations gradually increases during transit through the small intestine, and although intraluminal concentrations of 5-ASA are of importance for its therapeutic effects, the passage of 5-ASA has not been studied by direct analysis of the luminal contents from different levels of the small intestine.

The aims of this study were to determine the release of 5-ASA and the generation of its main metabolite, ac-5-ASA, from the slow release preparation Salofalk given as a single oral dose with a defined meal into the duodenum, midjejunum, and terminal ileum in healthy humans by direct, intraluminal measurements.

\section{Subjects and methods}

After giving informed consent, six healthy volunteers (men aged 25-35 years) participated in the study. The protocol was approved by the institution's ethics committee.

\section{GASTROINTESTINAL TUBES}

After an overnight fast, subjects were intubated with an 11 lumen polyvinyl oroileal tube that was placed with its tip in the distal ileum (240 to $250 \mathrm{~cm}$ from the mouth). In this position, 
aspiration ports were in the duodenum ( 5 to $10 \mathrm{~cm}$ proximal to the ligament of Treitz), the mid-jejunum ( 90 to $100 \mathrm{~cm}$ from the pylorus), and the distal ileum (150 to $160 \mathrm{~cm}$ from the pylorus). Ports for perfusion of non-absorbed marker and test solutions were at the papilla of Vater. Four additional catheters were perfused with deionised water and served as intestinal pressure recording ports; they were located about $10,40,70$, and $130 \mathrm{~cm}$ from the pylorus. Before the start and after the end of the study, tube position was verified by fluoroscopy.

\section{EXPERIMENTAL PROTOCOL}

After the tube had reached its correct position, continuous duodenal perfusion $(3 \mathrm{ml} / \mathrm{min})$ of polyethylene glycol 4000 (PEG; $15 \mathrm{mg} / \mathrm{ml}$; pH $7 \cdot 0$ ) as a luminal dilution marker and continuous recording of intestinal motility was begun. After an equilibration time of three hours, studies were started.

All subjects ingested a standardised semiliquid $300 \mathrm{ml}$ test meal ( $138 \mathrm{mg} / \mathrm{ml}$ starch; $34 \mathrm{mg}$ / $\mathrm{ml}$ triglycerides; $38 \mathrm{mg} / \mathrm{ml}$ sodium caseinate) (a gift from Dr Kessler, Fresenius AG, Oberursel, Germany) within 15 minutes. The test meal contained $100 \mu \mathrm{g} / \mathrm{ml}$ of phenolsulphonphthaleine (PSP) as a marker to assess emptying of the meal from the stomach and its transit through the small intestine. Together with the meal, subjects swallowed $500 \mathrm{mg}$ of 5-ASA (Salofalk, $250 \mathrm{mg}$ tablets; a gift from Dr Falk, Pharma GmbH, Freiburg, Germany).

From 30 minutes before up to 15 hours after the meal, 2 to $3 \mathrm{ml}$ aliquots of intraluminal contents were aspirated by hand from each aspiration site at 15 minute intervals and collected into vials that were immersed in ice; when the collectable volume was $<1 \mathrm{ml}$ within the 15 minute period, two consecutive samples were pooled to represent a $\mathbf{3 0}$ minute aliquot. To ensure rapid removal of fresh intraluminal samples, the tube to each site was flushed with a volume of air equal to its dead space (duodenal = $3 \mathrm{ml}$, jejunal $=4 \mathrm{ml}$, ileal $=5 \mathrm{ml}$ ) immediately before and after intestinal juice was aspirated. Venous blood samples were drawn at $\mathbf{3 0}$ minute intervals and urine was collected at two hour intervals for 14 hours.

\section{ANALYSES AND CALCULATIONS}

Gastrointestinal motility was recorded with a low compliance perfusion system (Sensormedics, Essen, Germany) and analysed as described previously. ${ }^{15} 16$ The 5-ASA and ac-5-ASA were measured in intestinal samples, plasma, and urine by high performance liquid chromatography. ${ }^{17}{ }^{18}$ Concentrations of PEG and PSP and $\mathrm{pH}$ were measured and after correction for the amounts removed proximally, were used to calculate intraluminal volume flow rates and delivery rates of 5-ASA and PSP to intestinal sites as described earlier. ${ }^{19-22}$ Briefly, the perfusion marker was used to compute luminal volume flow rates for each site during each aspiration interval. The 5-ASA and ac-5-ASA delivery rates were calculated at each site from the concentration in the aspirated aliquot sample and the volume flow rate associated with the same sample.

The digestive period was defined as the time between the ingestion of the test meal and occurrence of the first phase III motility in the duodenum; the remainder of the study was defined as the interdigestive period. Gastric emptying time after a meal was defined as the interval between start of the ingestion meal and cumulative delivery of $>90 \%$ of the meal marker PSP to the duodenal aspiration site, as described earlier. ${ }^{23}$ Time intervals between duodenal, jejunal, and ileal delivery of $50 \%$ of cumulative PSP recovered were used to calculate duodenojejuno-ileal transit times. Cumulative 5-ASA delivery to each aspiration site was defined as the cumulative amount released at this site corrected for cumulative PSP recovery and for the amount of chyme removed proximally. Data are expressed as mean (SD) values unless indicated otherwise.

\section{Results}

MOTILITY, GASTRIC EMPTYING, AND SMALL INTESTINAL TRANSIT OF TEST MEAL

Ingestion of the test meal induced a fed motility pattern in all subjects that was terminated by an interdigestive duodenal phase III activity front after 182 to 295 minutes (Fig 1). Cumulative delivery of $90 \%$ of the meal marker to the
Figure 1: (A) Intervals between ingestion of the test meal ( 0 minutes) and $90 \%$ cumulative duodenal delivery of meal marker ( $90 \%$ emptying; top bar), occurrence of the first duodenal phase III (middle bar) and first detection of 5-aminosalicylic acid in duodenal samples (bottom bar). Mean (SD) values of $n=6$. (B) Correlation of intervals between eatin meal and first duodenal phase III motility and first appearance of 5 aminosalicylic acid in duodenal samples $(p<0 \cdot 05)$.
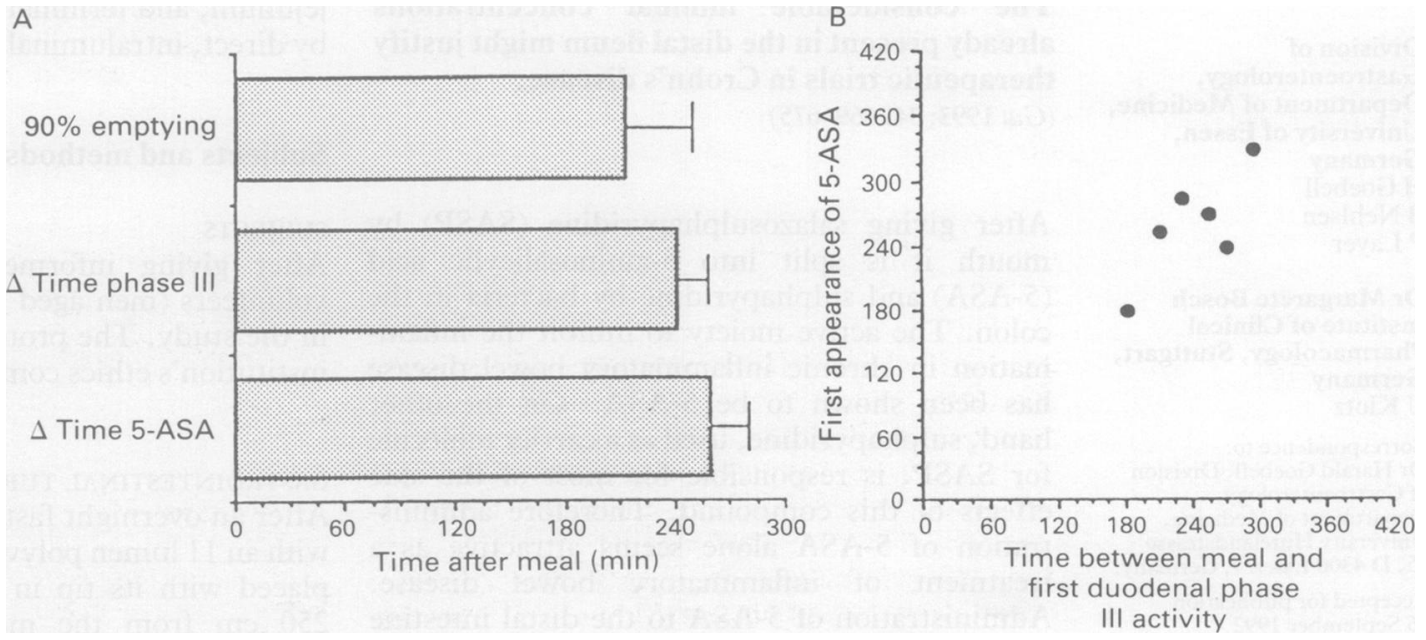

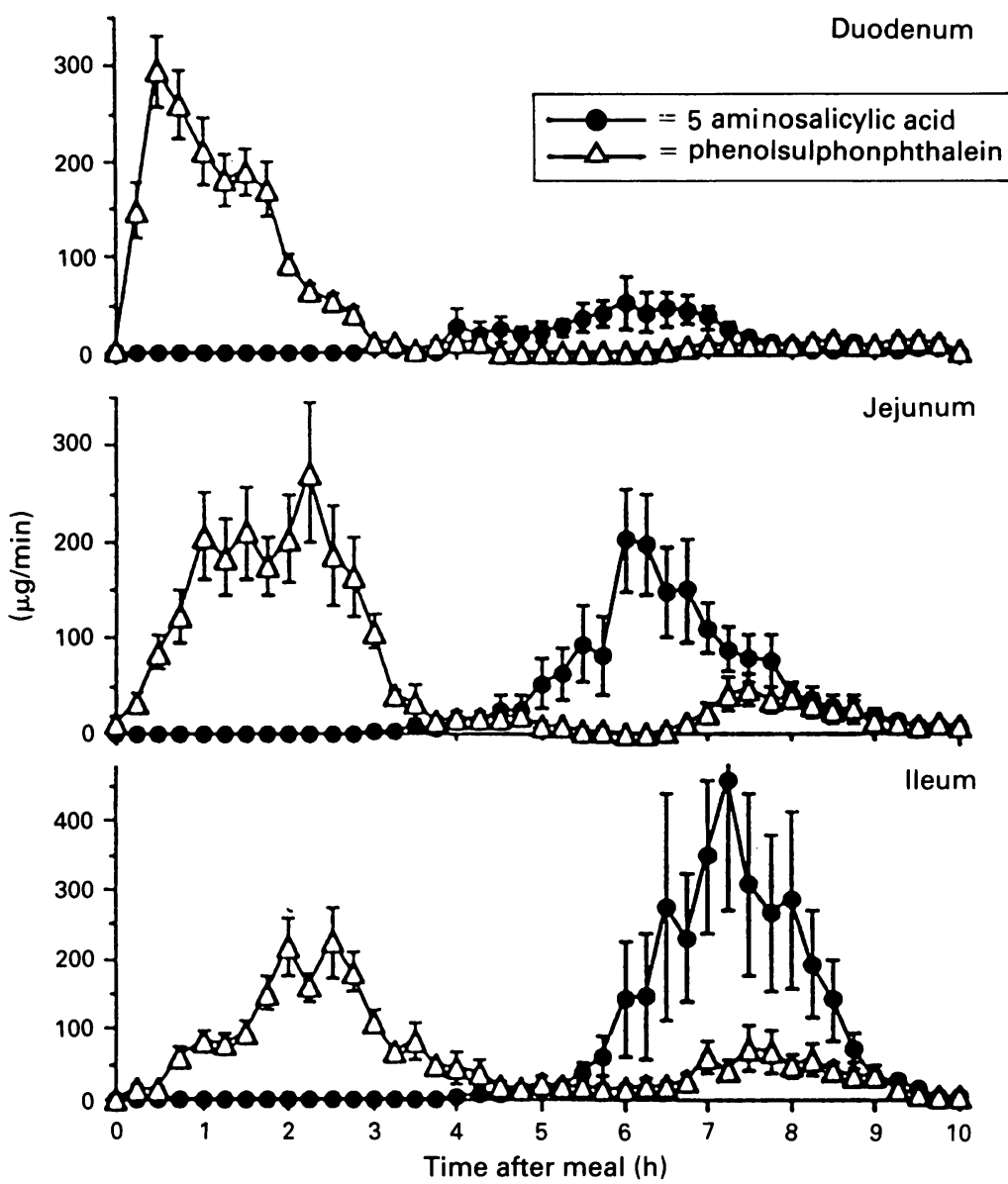

Figure 2: Delivery to duodenum, jejunum, and ileum of the meal marker phenolsulphonphthalein and release of 5 -

aminosalicylic acid from Salofalk tablets given with a meal ingested at 0 hours. Mean $(S D)$ values of $n=6$ duodenal aspiration site, which served as an estimate of gastric emptying of $90 \%$ of the meal, was exceeded after about three and a half hours (Figs 1 and 2). Thus at the time of the first duodenal phase III motility, $96 \cdot 6$ (SD 1.8)\% of the meal marker had left the stomach. Within this period, no 5-ASA or ac-5-ASA was detected in the small intestinal lumen, blood or urine. Small intestinal (duodenoileal) transit time of the meal marker was 169 (47) minutes and composed of duodenojejunal and jejunoileal transit times of 47 (10) minutes and 122 (51) minutes, respectively (Fig 2).

\section{INTRALUMINAL PH}

During the digestive period, mean luminal $\mathrm{pH}$ was $6.25(0.13)$ in the duodenum, $6.95(0.12)$ in the jejunum, and $7 \cdot 64(0 \cdot 16)$ in the ileum. During the subsequent interdigestive period, mean $\mathrm{pH}$ was $6.31(0.18)$ in the duodenum, 7.08 $(0 \cdot 18)$ in the jejunum, and $7 \cdot 81(0 \cdot 12)$ in the ileum.

DELIVERY OF 5-ASA AND AC-5-ASA TO INTESTINAL SITES

During the digestive period, no 5-ASA was detected in intestinal samples. Measurable quantities were present in duodenal aspirates after 180 to 330 minutes after the meal - that is, in the samples during or immediately after the first duodenal phase III motor pattern (Figs 1 and 2). Thus gastroduodenal delivery and duodenoileal transit of 5-ASA and Salofalk tablets were dissociated from those of the test meal (Fig 2) and release of 5-ASA occurred exclusively in the interdigestive period. The cumulative quantity of 5-ASA in solution in intestinal fluid at the duodenal aspiration site over the entire study period was $1.5 \%$ of the dose administered; cumulative duodenal occurrence of ac-5-ASA was $1 \cdot 4 \%$ (Table I). Cumulative values of dissolved 5-ASA and ac-5-ASA in the jejunum were $5 \cdot 7 \%$ and $11 \cdot 7 \%$ respectively, and in the ileum $12 \cdot 7 \%$ and $17 \cdot 9 \%$ respectively (Table 1).

\section{LUMINAL CONCENTRATIONS OF 5-ASA AND AC-5-ASA}

Luminal concentrations of 5-ASA increased continuously between proximal and distal aspiration sites within each subject $(\mathrm{p}<0.01)$. In the duodenum, concentrations of 5-ASA and ac-5-ASA were in the same range, but at the two distal aspiration sites ac-5-ASA concentrations tended to be higher than 5-ASA concentrations: For one to two hours, mean intraduodenal concentrations either compound were 15 to $30 \mu \mathrm{g} / \mathrm{ml}$. By contrast, mean intrajejunal concentrations of 5-ASA were 30 to $70 \mu \mathrm{g} / \mathrm{ml}$, and of ac-5-ASA 50 to $130 \mu \mathrm{g} / \mathrm{ml}$; mean intraileal concentrations of 5-ASA were 60 to $110 \mu \mathrm{g} / \mathrm{ml}$, and of ac-5-ASA 80 to $150 \mu \mathrm{g} / \mathrm{ml}$; however, there were large interindividual variations (Fig 3).

Peak concentrations of 5-ASA and ac-5-ASA at the duodenal aspiration site were found after mean intervals of $6.2(0.4)$ hours and $6.3(0.4)$ hours after the meal, at the jejunal sites after 6.6 $(0.4)$ hours and $6.8(0.3)$ hours, and at the ileal site after $7.4(0.3)$ hours and $7.5(0.3)$ hours, respectively (Fig 2 ).

\section{5-ASA AND AC-5-ASA IN PLASMA AND URINE}

First appearance and the first peak concentration of 5-ASA in the plasma were recorded after a mean interval of four hours and $6 \cdot 5(0 \cdot 2)$ hours after the meal respectively, and thus paralleled delivery to the duodenum (Fig 3). Up to the end of the seventh postprandial hour, plasma ac-5ASA and 5-ASA concentrations were similar. By contrast, over the subsequent two hours, plasma 5-ASA concentrations decreased, but ac-5-ASA concentrations increased further and exhibited two distinct, separate peaks, the first after $6.9(0.2)$ hours, the second after $8.6(0.3)$ hours (Fig 3). Thus the first plasma peak after 6.9 hours occurred during major release of 5-ASA and formation of ac-5-ASA in the distal

TABLE I Cumulative load of 5-aminosalicylic acid (5-ASA) and Acetyl-5-ASA (ac-5-ASA) released during transit through small intestine and delivered to duodenal, jejunal, and ileal aspiration sites, and excreted in urine, during 10 hours after ingestion of $500 \mathrm{mg}$ of 5-ASA as $250 \mathrm{mg}$ Salofalk tablets (mean $(S D)$ values of $n=6$ ).

\begin{tabular}{|c|c|c|c|c|}
\hline & \multicolumn{2}{|l|}{ 5- $A S A$} & \multicolumn{2}{|l|}{$A c-5-A S A$} \\
\hline & $(m g)$ & $(\%$ dose $)$ & $(m g)$ & (\% dose $)$ \\
\hline $\begin{array}{l}\text { Duodenum } \\
\text { Jejunum } \\
\text { Ileum } \\
\text { Urine }\end{array}$ & $\begin{array}{r}7 \cdot 5(3 \cdot 2) \\
28 \cdot 3(7 \cdot 2) \\
63 \cdot 5(20 \cdot 2) \\
1 \cdot 0(0 \cdot 5)\end{array}$ & $\begin{array}{r}1 \cdot 5 \\
5 \cdot 7 \\
12 \cdot 7 \\
0 \cdot 2\end{array}$ & $\begin{array}{r}6.9(1.4) \\
58 \cdot 7(11.5) \\
89 \cdot 3(26 \cdot 5) \\
36 \cdot 5(17 \cdot 5)\end{array}$ & $\begin{array}{r}1 \cdot 4 \\
11 \cdot 7 \\
17 \cdot 9 \\
7 \cdot 3\end{array}$ \\
\hline
\end{tabular}



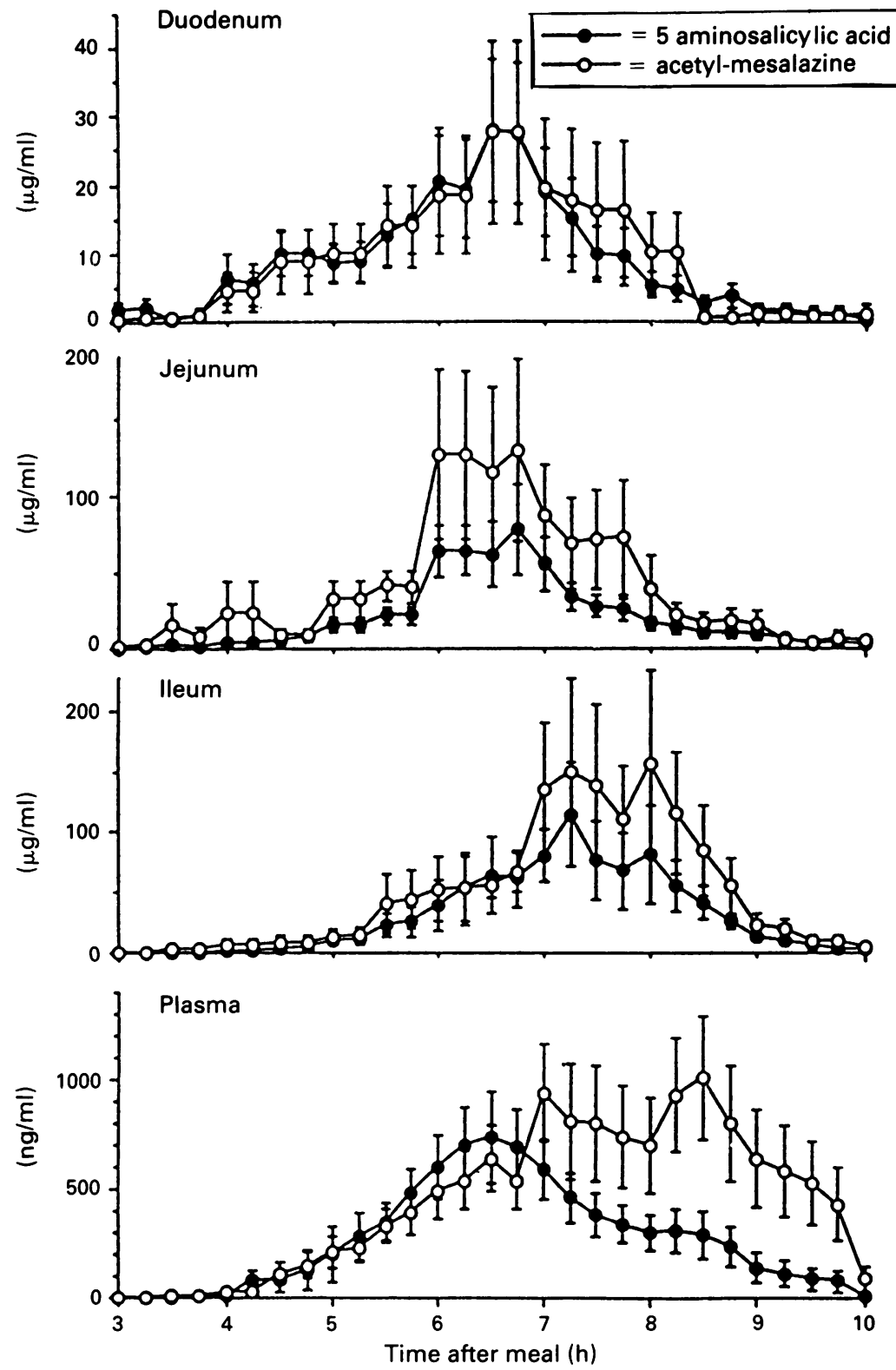

Figure 3: Concentration of 5-aminosalicylic acid and acetyl-mesalazine (ac-5-ASA) in duodenal, jejunal, and ileal lumen and plasma, after ingestion of Salofalk 250 tablets $(500 \mathrm{mg}$ mesalazine) with a meal at 0 hours. Mean $(S D)$ values of $n=6$. small intestine, the second peak after the major proportion after 8.6 hours had passed into the colon.

Only small amounts of 5-ASA were excreted in the urine $(0 \cdot 2 \%$ of 5 -ASA dose). About $7 \cdot 3 \%$ of the administered dose were recovered as ac-5ASA over the 10 postprandial hours (Table I).

\section{Discussion}

Our findings show that 5-ASA tablets with acid resistant coating (Salofalk tablets) given with a meal are emptied into the small intestine not during the digestive period, but with the beginning of the subsequent interdigestive phase III motor activity. During small intestinal transit, intraluminal concentrations of 5-ASA and its main metabolite, ac-5-ASA, gradually increase; at the ileal aspiration site more than $30 \%$ of the total dose has been released from the preparation into the the gut lumen and could be determined as either 5-ASA or ac-5-ASA. Concentrations of 5-ASA in the plasma parallel those in the proximal small intestine, whereas plasma ac-5ASA peaks appear later and correspond more to the 5-ASA release in the terminal ileum and in the colon.

The main site of inflammation in extended ulcerative colitis is the colon up to the caecal region and in Crohn's disease the distal ileum and proximal part of the colon, the ileum being involved in $75 \% .{ }^{24}$ Oral plain 5-ASA is rapidly absorbed in the upper intestine ${ }^{2-4}$; therefore, the galenics of an oral 5-ASA preparation have to be modified to deliver sufficient quantities of 5-ASA to the lower small bowel and colon. In Crohn's ileitis, slow delivery of 5-ASA from a slow release preparation has a theoretical advantage over other galenic approaches because it may liberate sufficient quantities of the compound already in the ileum. The fate of a slow release preparation in the small intestinal lumen is determined by gastric emptying and small intestinal transit, intraluminal $\mathrm{pH}$, and the specific coating of the tablet. We studied a preparation that contained 5-ASA in a sodium carbonate-glycine buffering mixture and an acid resistant coating of an acrylic based resin (Eudragit L 100, Salofalk, identical with Claversal). This coating disintegrates and releases 5-ASA at and above $\mathrm{pH} 6 \cdot 0$, the prevailing $\mathrm{pH}$ in the mid and lower small intestine and colon.

Our findings suggest that 5-ASA was not emptied from the stomach with the test meal, but with the first phase III motor complex of the subsequent interdigestive period. Because only particles of $<1-2 \mathrm{~mm}$ are emptied in the prandial period, this suggests that no intragastric disintegration of tablets occurred. These findings are in agreement with data by Hardy et al who used indium-111-labelled 5-ASA containing tablets covered by an Eudragit L film (Claversal $=$ Salofalk) which were emptied from the stomach after four hours when taken with a meal, and after less than one hour when taken in the fasting state. ${ }^{9}$ Meyer et al have shown that particles larger than $3 \mathrm{~mm}$ are retained in the stomach and emptied postprandially. ${ }^{25}$ This point has been further established by Ewe $e t a l^{26}$ who showed that larger particles are retained in the stomach irrespective of the composition of the meal (liquid or solid). Not only gastric emptying, but also small intestinal transit of the test meal and the tablets together with released 5-ASA are thoroughly dissociated. This suggests that even when ingested with a meal, 5-ASA from the tablets may not mix with, or adsorb to, meal components. To avoid discontinuous release of 5-ASA in the gut with several meals over the day, the practical consequence therefore should be to take the tablets about half an hour before a meal in the fasting state. Release of 5-ASA into the lumen began in the duodenum at pH 6 to 7 and increased significantly during small intestinal transit of the tablets, suggesting progressive release due to increasing permeability of the coating. Disintegration of the coating was likely further accelerated by gradually increasing $\mathrm{pH}$ between the duodenal and the ileal aspiration site, with a prevailing $\mathrm{pH}$ of $>7$ in the distal lumen. An elegant measurement of the $\mathrm{pH}$-profile in the small and large bowel was published by Evans $e t a l$, with a radiotelemetry capsule. ${ }^{27}$ These data show a mean $\mathrm{pH}$ of 6.6 $(0.5)$ in the proximal small bowel and of $7 \cdot 5(0.4)$ 
in the terminal ileum. Our direct $\mathrm{pH}$ measurements in the intestinal fluids are in good agreement with these data. It is interesting that Evans et al found a decrease of the $\mathrm{pH}$ to $6.4(0.4)$ in the coecal region with a final mean $\mathrm{pH}$ of $7 \cdot 0(0 \cdot 7)$ in the left colon. These values would mean that a continuous release of 5-ASA from the tablets can take place also in the colon. Our data suggest that the ileal mucosa was exposed to free 5-ASA concentrations of $>50 \mu \mathrm{g} / \mathrm{ml}$ for two hours, whereas concentrations and duration of exposure were lower at proximal intestinal sites.

From the first appearance of 5-ASA in the duodenum, ac-5-ASA was also present in the intestinal fluid. The ratio of 5-ASA to ac-5-ASA was about $1: 1$ in the duodenum, and $1: 1.5$ to $1: 2$ in the distal small intestine. This may be true only for the low dose used in this study. Because acetylation of 5-ASA by intestinal mucosal acetyltransferase follows a saturation kinetic, ${ }^{12}$ the 5-ASA to ac-5-ASA ratio might increase after higher doses of 5-ASA. ${ }^{10}$ Mardini et al ${ }^{28}$ have reported a proportion of 5-ASA to ac-5-ASA in the colon lumen of $2 \cdot 4$. This might reflect the finding that the absorption rate of 5-ASA is lower in the colon than in the small bowel. ${ }^{29}$

Initially, concentrations of 5-ASA and ac-5ASA in the plasma were similar, and their kinetics paralleled those in the duodenal and jejunal lumen. This suggests rapid absorption in the proximal part of the small intestine and rapid metabolism that likely occurs in part presystemically. Peak concentrations of 5-ASA were lower and reached earlier than those of ac-5ASA. Thereafter concentrations of the metabolite were considerably higher than those of the parent drug due to the slower elimination of the metabolite. ${ }^{13}$ After a single oral dose of the same preparation similar mean concentration profiles as measured in our study were found both in healthy subjects and in patients with inflammatory bowel disease ${ }^{30} 31$ in another study initially higher concentrations of the metabolite were reported. ${ }^{32}$ Considerable interindividual variations in the disposition of 5-ASA have been shown during pharmacokinetic studies with 5-ASA.

The cumulative amount of 5-ASA and ac-5ASA that was excreted in the urine within 10 hours (that is six to seven hours after the start of 5-ASA emptying into the duodenum) was $<10 \%$ of the total dose. This value is within the range of other studies; it represents an underestimation because 5-ASA and especially the slowly eliminated ac-5-ASA can be detected in the urine up to 96 hours. ${ }^{4}$ In this study, Rijk et al reported a urinary excretion of about $10 \%$ within the first eight hours, $20 \%$ within 24 hours, and 34\% within 96 hours. ${ }^{4}$ In combination, these findings suggest that up to one third of an oral dose of 5-ASA is excreted in urine, and that absorption of the major portion occurs not during small intestinal transit but in the colon.

We found a total ileal cumulative load of 5-ASA and ac-5-ASA of about $30 \%$ of the oral dose, and an early urinary excretion of $<10 \%$. Thus our data suggest that about $60 \%$ of the dose should have reached the colonic lumen still in tablets and another $15 \%$ as solubilised 5-ASA (Table II). Our data were obtained from healthy volunteers. In active inflammatory bowel disease the transit through the small bowel was found to be not different from the healthy state, ${ }^{9}{ }^{30}$ but the authors had studied only patients with Crohn's disease without a stricture and with ulcerative colitis. It is possible that the transit through the small bowel is changed with the presence of strictures and that tablets could be retained by strictures that could change the pattern of 5-ASA release in the small bowel. In ulcerative colitis it was shown by Rao $e t a l^{3}$ that transit in the small intestine may be slower than normal. This would mean that more 5-ASA would be acetylated and absorbed before colonic arrival. ${ }^{34}$ Based on indirect estimates, a colonic availability of $66 \%$ has been proposed by Rijk et $\mathrm{al}^{4}$; the same group has also measured fecal excretion, which was reported to be $37 \%$ of the total dose in 96 hours; only $5 \%$ was present as 5 -ASA and $31 \%$ as ac-5ASA. Measurements of faecal contents may be difficult to interpret, however, because 5-ASA might be degraded by colonic bacteria to ac-5$\mathrm{ASA}^{35}$ and to unknown products. ${ }^{4}$

It has been shown that 5-ASA is the active anti-inflammatory moiety in chronic inflammatory bowel disease, whereas the acetylated metabolite seems inactive. ${ }^{3637}$ The uptake of 5-ASA in colonic cell preparations occurs rapidly and is equivalent to the production of ac-5-ASA by the cells, whereas the uptake of acetylated 5-ASA is slower. ${ }^{36-38}$ Not all 5-ASA penetrating the intestinal mucosa is acetylated, however, because our data confirm that a small portion also enters the systemic blood without prior acetylation.

Intestinal acetylation of 5-ASA occurs rapidly within the intestinal mucosa ${ }^{179}$ whereas no acetylation was found during incubation in human duodenal, jejunal, and ileal juice (our own unpublished observations); this suggests that intraluminal acetylation does not play a major part in the generation of intraluminal ac-5ASA in the small intestine. In the colon, the colonic mucosa is also the major site of acetylation of 5-ASA. ${ }^{17}$ Allgayer $e t a l^{17}$ showed that the colonic mucosa acetylates $370(20) \mathrm{nmol} / \mathrm{g}$ wet weight of tissue per minute. In comparison the acetylation in faecal samples by bacteria was lower $(13.0(3.0) \mathrm{nmol} / \mathrm{g})$. Nevertheless, this means that the luminal colonic content also contributes to the inactivation of 5-ASA. Another factor that influences the availability of 5-ASA to the mucosa in ulcerative colitis is the finding that different 5-ASA preparations show a considerable variation in colonic 5-ASA concentrations. ${ }^{35}$ Almost double intraluminal concentrations were found with olsalazine compared

TABLE II Overall calculation of the fate of 5-ASA swallowed in a slow release tablet (Salofalk).

\begin{tabular}{lc}
\hline 5-ASA+ac-5-ASA & \\
\hline Swallowed in tablet & $100 \%$ \\
Solubilised in ileum & $30 \%$ \\
Excreted in urine & $10 \%$ \\
Unreleased in ileum & $60 \%$ \\
After 8 to $10 \mathrm{~h}$ & All substance has left the small bowel \\
Entered into the colon & $60 \%$ unreleased in tablet \\
& $30 \%$ in solution (about $15 \%$ as 5-ASA; \\
& about $15 \%$ as ac-5-ASA) \\
Totally into the colon & $90 \%$ of the given dose, 75\% as 5-ASA \\
By 8 to $10 \mathrm{~h}$ & $10 \%$ excreted in urine \\
\hline
\end{tabular}


with equimolar doses of Pentasa and Salofalk.

For a positive effect of 5-ASA in ulcerative colitis the concentration in the colonic lumen should be high enough to build up a gradient for absorption into the mucosa. So higher doses of slow release preparations than olsalazine are needed theoretically for therapeutic use in ulcerative colitis. There is no evidence for major enterobiliary recirculation and biliary resecretion of acetyl-5-ASA, ${ }^{40}$ as assessed from kinetics of luminal concentrations at all intestinal aspiration sites as well as in plasma. Thus the considerable intraluminal quantities of ac-5-ASA suggest that 5-ASA may have entered the intestinal mucosa and, after acetylation, have partly back diffused into the lumen. As most of the 5-ASA entering the mucosal cell is acetylated, it seems conceivable that its anti-inflammatory action within the tissue occurs before the acetylation step. We therefore speculate that in the small bowel the intraluminal ac-5-ASA represents the portion that already may have exerted anti-inflammatory action within the tissue and that the free intraluminal 5-ASA represents the portion that has not yet penetrated into the mucosa. Thus it may be misleading to assess the anti-inflammatory potential of 5-ASA based only on its intraluminally available free concentration.

In conclusion this study shows, by direct luminal measurements, that in healthy subjects delayed release of 5-ASA from Salofalk tablets occurs with its major release into the colon. Although the kinetics of this single dose study may differ from those present in patients with chronic treatment, these data might explain the effectiveness of 5-ASA in acute phase and maintenance treatment of ulcerative colitis. ${ }^{412}$ Yet the considerable release to the ileal lumen may warrant a trial of its use in Crohn's ileitis. One such trial has been published with promising results in maintaining remission of inactive Crohn's disease. ${ }^{43}$ This has to be proved in further studies. Evidence is still needed from studies that it also works in active Crohn's disease.

This work was supported by Deutsche Forschungsgemeinschaft

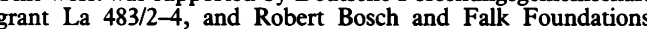
Stuttgart and Freiburg, Germany. We thank L Cherian and B Mauch for expert technical assistance and $\mathrm{H}$ Lütticke, $M$ Wissmann and C Brockner for secretarial assistance.

1 Azad Khan AK, Piris J, Truelove SC. An experiment to determine the active therapeutic moiety of sulphasalazine. Lancet 1977; 1: 892-5.

2 Nielsen $\mathrm{OH}$, Bondensen S. Kinetics of 5-aminosalicylic acid after jejunal instillation in man. Br $\mathcal{F}$ Clin Pharmacol 1983; 16: $738-40$.

3 Myers B, Evans DNW, Rhodes J, Evans BK, Hughes BR, Lee MG, et al. Metabolism and urinary excretion of 5-aminosalicylic acid in healthy volunteers when given intravenously
or released for absorption at different sites in the gastroor released for absorption at different
intestinal tract. Gut 1987; 28: 196-200.

4 Rijk MCM, van Schaik A, van Tongeren JHM. Disposition of 5-aminosalicylic acid by 5-aminosalicylic acid-delivering compounds. Scand $\mathcal{F}$ Gastroenterol 1988; 23: 107-12.

5 Rasmussen SN, Bondesen S, Huidberrg EF, Hansen SH Binder $\mathrm{U}$, Halskov $\mathrm{S}$, et al. 5-aminosalicylic acid in a slow release preparation: bioavailability, plasma level and excretion in humans. Gastroenterology 1982; 83: 1062-70.

$6 \mathrm{Klotz}$ U, Maier KE, Fischer C, Bauer KH. A new slow-release form of 5-aminosalicylic acid for the oral treatment of inflammatory bowel disease. Biopharmaceutical and clinica pharmacokinetic characteristics. Drug Res 1985 ; 35: 636-9.

7 Klotz U, Seyffer R, Allgayer H, Maier KE. Pharmacokinetic properties of mesalazine (5-aminosalicylic acid). In: McDermott RP, ed. Inflammatory bowel disease. New York: Elsevier 1988; 725-9.

8 Klotz U. Pharmacokinetic properties of 5-amino-salicylicacid (mesalazine). In: Goebell H, Peskar BM, Malchow H, eds Inflammatory bowel diseases - basic research and clinical implications. Lancaster: MTP Press 1988; 339-47. Falk Symposium No 46

9 Hardy JG, Healey JNC, Lee SW, Reynolds JR. Gastrointestinal transit of an enteric-coated delayed-release 5 aminosalicylic acid tablet. Aliment Pharmacol Therap 1987; 1: 209-16.

10 Riley SA, Tavares IA, Bennett A, Mani V. Delayed-release mesalazine (5-aminosalicylic acid): coat dissolution and excretion in ileostoma subjects. Br f Clin Pharmacol 1988; 26: 173-7.

11 Christensen LA, Fallingborg J, Abildgaard K, Jacobsen BA, Sanchez G, Hansen SH, et al. Topical and systemic availability of 5-aminosalicylate: comparisons of three controlled release preparations in man. Aliment Pharmacol Therap 1990; 4: 523-33.

12 Klotz U. Clinical pharmacokinetics of sulphasalazine, its metabolites and other products of 5-aminosalicylic acid. Clin Pharmacokinet 1985; 10: 285-302.

13 Brogden RN, Sarkin EM. Mesalazine: a review of its pharmacodynamic and pharmacokinetic properties, and therapeutic potential in chronic inflammatory bowel disease. Drugs 1989; 38: 500-23.

14 Jarnerot G. Newer 5-aminosalicylic acid based drugs in chronic inflammatory bowel disease. Drugs 1989; 37:

$73-86$.
15 Layer P, Chan ATH, Go VLW, DiMagno EP. Human pancreatic secretion during phase II antral motility of the
interdigestive cycle. Am $\mathcal{F}$ P hysiol 1988; 254: G249-53.

16 Layer P, Peschel S, Schlesinger T, Goebell H. Human pancreatic secretion and intestinal motility: effects of ileal nutrient perfusion. Am F Physiol 1990; 258: G196-G201.

17 Allgayer H, Ahnfelt NO, Kruis W, Klotz U, Frank-Holmberg $\mathrm{K}$, Söderberg HNA, et al. Colonic N-acetylation of 5aminosalicylic acid in inflammatory bowel disease. Gastroenterology 1989; 97: 38-41.

18 Fischer C, Maier K, Klotz U. Simplified high-performance liquid chromatographic method for 5-aminosalicylic acid in plasma and urine. $\mathcal{f}$ Chromatography 1981; 225: 498-503.

19 Go VLW, Hofmann AF, Summerskill WHJ. Simultaneous measurements of total pancreatic, biliary, and gastric outputs in man using a perfusion technique. Gastroenterology 1970; 58: 321-8.

20 Wingate DL, Sandberg RJ, Phillips SF. A comparison of stable and $14 \mathrm{C}$-labelled polyethylene glycol as volume indicators in the human jejunum. Gut 1972; 13: 812-5.

21 Layer P, Zinsmeister AR, DiMagno EP. Effects of decreasing intraluminal amylase activity on starch digestion and postprandial gastrointestinal function in humans. Gastroenterology 1986; 91: 41-8.

22 Layer P, Jansen JBMJ, Cherian L, Lamers CBHW, Goebell H. Feedback regulation of human pancreatic secretion: effects of protease inhibition on duodenal delivery and small intestinal transit of pancreatic enzymes. Gastroenterology 1990; 98: 1311-9.

23 Layer P, Go VLW, DiMagno EP. Fate of pancreatic enzymes during aboral small intestinal transit in humans. Am $\mathcal{F}$ Physiol 1986; 251: G475-80.

24 Goebell H, Förster S, Dirks E, Scharschmidt K, Eigler FW. Crohn's disease: the clinical pattern of the disease in relation to localisation. A prospective analysis of 300 patients. Med Clin 1987; 82: 1-8.

25 Meyer JH, Elashoff J, Porter-Fink V, Dressman J, Amidon GL. Human postprandial emptying of 1-3 mm spheres. Gastroenterology 1988; 94: 1315-20.

26 Ewe K, Press AG, Bollen S, Schuhn J. Gastric emptying of indigestible tablets in relation to composition and time of ingestion of meals studied by metal detector. Dig Dis $S c i$ 1991; 36: 146-52.

27 Evans DF, Pye G, Bramley R, Clark AG, Dyson TJ, Hardcastle JD. Measurement of gastrointestinal $\mathrm{pH}$ profiles in normal ambulant human subjects. Gut 1988; 29: 1035-41.

28 Mardini HAL, Lindsay DC, Deighton CM, Record CO. Effect of polymer coating on faecal recovery of ingested 5aminosalicylic acid in patients with ulcerative colitis. Gut 1987; 28: 1084-9.

29 Bondesen S, Bronnum-Schon J, Pedersen V, Rafiolsadat Z, Honore-Hansen S, Huidberg EF. Absorption of 5-aminosalicylic acid from colon and rectum. Br $\mathcal{F}$ Clin Pharmacol 1988; 25: 269 .

30 Hardy JG, Healey JNC, Reynolds JR. Evaluation of an enteric-coated delayed-release 5-aminosalicylic acid tablet in patients with inflammatory bowel disease. Aliment Pharmacol Therap 1987; 1: 273-80.

31 Norlander B, Gotthard R, Ström M. Pharmacokinetics of a 5aminosalicylic enteric-coated tablet in patients with Crohn's disease or ulcerative colitis and in healthy volunteers. Aliment Pharmacol Therap 1990; 4: 497-505.

32 Norlander B, Gotthard R, Ström M. Pharmacokinetics of a 5aminosalicylic acid enteric -coated tablet and suppository aminosalicylic acid enteric -coated tablet and supposito
dosage form. Aliment Pharmacol Therap 1989; 3: 333-42.

33 Rao SSC, Read NW, Holdsworth CD. Gastrointestinal transit and stool output in the pathophysiology of diarrhea in ulcerative colitis (UC) [Abstract]. Clin Sci 1986; 72 (suppl 15): 41 .

34 Rijk MCM, van Hogerzand RA, van Schaik A, van Tongeren JHM. Disposition of 5-aminosalicylic acid from 5-aminosalicylic acid delivering drugs during accelerated intestinal transit in healthy volunteers. Scand $\mathcal{F}$ Gastroenterol 1989; 24: 1179-85.

35 Laursen LS, Stokholm M, Bukhave K, Rask-Madsen J, Lauritsen K. Disposition of 5-aminosalicylic acid by olsalazine and three mesalazine preparations in patients with ulcerative colitis: comparison of intraluminal colonic concentrations, serum values, and urinary excretion. Gut 1990; 31: $1271-6$. 
36 Binder V, Halskov S, Hvidberg E, Kristensen E, Ruis P, Tongaard L, et al. A controlled study of 5-acetyl-aminosalicylic acid (5-Ac-ASA) as enema in ulcerative colitis. Scand $\mathcal{F}$ Gastroenterol 1981; 16: 1122.

37 van Hogezand RA, van Hees PAM, van Gorp JPWM, van Lier HJJ, Bakker JH, Wesseling P, et al. Double-blind comparison of 5-aminosalicylic acid and acetyl-5-aminosalicylic acid suppositories in patients with idiopathic proctitis.

38 Aliment Pharmacol Therap 1988; 2: 33-40.

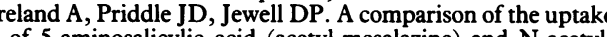
of 5-aminosalicylic acid (acetyl-mesalazine) and $\mathrm{N}$-acetylaminosalicylic acid (Ac-ASA) into the isolated colonic epithelial cell. Gastroenterology 1987; 92: 1447.

39 Ireland A, Priddle JD, Jewell DP. Acetylation of 5-aminosalicylic acid by human colonic epithelial cells. Gastroenterology 1986; 90: 1471 .
40 Fischer C, Maier K, Klotz U. Specific measurement of 5aminosalicylic acid and its acetylated metabolite in human bile. Br F Clin Pharmacol 1983; 15: 273-4.

41 Riley SA, Mani V, Goodman MJ, Herd ME, Dutt S, Turnberg LA. Comparison of delayed-release 5-aminosalicylic acid (5-ASA) and sulfasalazine as maintenance treatment for patients with ulcerative colitis. Gastroenterology 1988; 94: patients

42 Rachmelewitz D. On behalf of an international study group. Coated 5-ASA versus sulphasalazine in the treatment of active ulcerative colitis: A randomised trial. $B$ Med $\mathcal{F} 1989$; 298: 82-6.

43 Thomson ABR and the International Mesalazine Study Group. Coated oral 5-aminosalicylic acid versus placebo in maintaining remission of inactive Crohn's disease. Aliment Pharmacol Therap 1990; 4: 55-64. 